\title{
Continuous Cultivation as a Method to Assess the Maximum Specific Growth Rate of Photosynthetic Organisms
}

\author{
Elena Barbera ${ }^{1,2}$, Alessia Grandi ${ }^{1}$, Lisa Borella ${ }^{2}$, Alberto Bertucco ${ }^{2}$ and Eleonora Sforza ${ }^{1 *}$ \\ ${ }^{1}$ Interdepartmental Center Giorgio Levi Cases, University of Padova, Padova, Italy, ${ }^{2}$ Department of Industrial Engineering DII, \\ University of Padova, Padova, Italy
}

\section{OPEN ACCESS}

Edited by:

Atul Narang,

Indian Institute of Technology

Delhi, India

Reviewed by:

Ernani Pinto,

University of São Paulo, Brazil

Ankush Karemore,

Georgia Institute of Technology,

United States

${ }^{*}$ Correspondence:

Eleonora Sforza

eleonora.sforza@unipd.it

$$
\begin{array}{r}
\text { Specialty section: } \\
\text { This article was submitted to } \\
\text { Bioprocess Engineering, } \\
\text { a section of the journal } \\
\text { Frontiers in Bioengineering and } \\
\text { Biotechnology }
\end{array}
$$

Received: 09 July 2019 Accepted: 01 October 2019 Published: 17 October 2019

Citation:

Barbera E, Grandi A, Borella L, Bertucco A and Sforza E (2019) Continuous Cultivation as a Method to

Assess the Maximum Specific Growth

Rate of Photosynthetic Organisms.

Front. Bioeng. Biotechnol. 7:274.

doi: 10.3389/fbioe.2019.00274
Modeling the growth of photosynthetic organisms is challenging, due to the complex role of light, which can be limiting because of self-shading, or photoinhibiting in the case of high intensities. A case of particular interest is represented by nitrogen-fixing cyanobacteria, whose growth is controlled not only by the light intensity, but also by the availability of atmospheric nitrogen in the liquid medium. The determination of the maximum specific growth rate is often affected by many variables that, in batch growth systems, may change significantly. On the other hand, in a continuous system, once the steady state is reached the values of all the process variables remain constant, including the biomass concentration and the specific light supply rate. In this work, the diazotrophic cyanobacterium Anabaena PCC 7122 was cultivated in continuous photobioreactors, to investigate the role of nitrogen, light and residence time on growth kinetics, and to retrieve the value of the maximum specific growth rate of this organism. In addition, the kinetic parameters for temperature and the half saturation constant for nitrogen $\left(3 \mathrm{mg} \mathrm{L}^{-1}\right)$ were measured by respirometric tests. Based on the results of continuous experiments, the specific maintenance rate was found to depend on the light intensity supplied to the reactor, ranging between 0.5 and $0.8 \mathrm{~d}^{-1}$. All these parameters were used to develop a kinetic model able to describe the biomass growth in autotrophic conditions. The maximum specific growth rate could hence be determined by applying the kinetic model in the material balances of the continuous photobioreactor, and resulted equal to $8.22 \pm$ $0.69 d^{-1}$.

Keywords: cyanobacteria, Anabaena PCC7122, kinetic model, respirometry, continuous photobioreactors

\section{INTRODUCTION}

Photosynthetic microorganisms, such as microalgae and cyanobacteria, have recently gained researchers' interest due to their great potentialities. For example, they can double their cells even 100 times faster than terrestrial plants (Lam et al., 2012) and require significantly less area to grow with respect to other crops thanks to their high photosynthetic efficiency per unit surface (Darvehei et al., 2018). Moreover, they offer a large number of potential applications: the biomass can be used directly (e.g., in aquaculture), or in environmental applications (e.g., waste water treatment, $\mathrm{CO}_{2}$ mitigation and biofuel production), or alternatively high-value compounds can be extracted (e.g., pigments, vitamins) (Fernandes et al., 2015). 
Large-scale cultivation of microalgae and cyanobacteria to produce bioproducts and biofuels has greatly increased over the last years (Khan et al., 2018). However, there are still many challenges to face. The most important is represented by the need to increase the process profitability, which is mainly influenced by the biomass productivity. In order to maximize the productivity, the process operating conditions must be optimized and strictly controlled. An important contribution is given by mathematical models that take into account the effect of each process variable (light, temperature, residence time, etc.) for the estimation of key production parameters (biomass growth rate, productivity, etc.) (Darvehei et al., 2018). In addition, they can be used to bridge the existing gap between lab-scale observations, on which prediction of the growth on large scale is based, and the industrial-scale reality (Bernard et al., 2015).

However, modeling the growth of photosynthetic organisms, as well as control and optimization of the process, is challenging, even more than for bacterial or yeast bioprocesses. This is mainly due to higher complexity of their cells and the wide range of mechanisms they use to respond to, or protect themselves from changes in light intensity, temperature and other environmental factors (Bernard et al., 2015).

One of the most important parameters to be determined is the maximum specific growth rate $\left(\mu_{\max }\right)$. In general, it is evaluated by cultivating the microorganism in batch systems and subsequently elaborating the experimental data obtained during the exponential phase of growth. However, it is important to notice that the value of $\mu_{\max }$ determined this way is affected by the experimental conditions, such as light intensity, temperature, $\mathrm{pH}$ and medium composition, which are not constant during the growth since biomass, substrates and products concentrations all change exponentially (Stanbury et al., 2016). In particular, the actual light perceived by the cells drops along with the increase of biomass concentration. In this way, the microorganism cannot adapt to the environment in which it is growing, since the adaptation process is not instantaneous (Trilli, 1990). Therefore, it is very difficult to relate "cause and effect" by growing the microorganism in batch systems.

On the other hand, in a continuous system, the growth rate is controlled by the dilution rate (Stanbury et al., 2016) and, once the steady state is reached, the values of all the process variables remain constant, including the biomass and substrate concentrations, and especially the specific light supply rate. Moreover, the adaptation process is no longer a problem because the microorganism is let to adapt to the growing conditions during the transient phase. This allows a quantitative assessment of the effect of the operating variables on the performances of the culture.

In this work, we propose a new approach that combines the use of cultivation in continuous systems and respirometric tests to determine the kinetic parameters of photosynthetic microorganisms' growth (Sforza et al., 2019). In particular, it was applied to study the growth of the nitrogen-fixing cyanobacterium Anabaena PCC 7122, which is not only affected by the light intensity, but also by the liquid solubility of atmospheric nitrogen, that controls its availability in the culture medium. The cultivation of diazotrophic cyanobacteria can find promising applications toward the development of a sustainable agriculture (Singh and Datta, 2007), or in the production of valuable pigments, such as phycocyanin (Moreno et al., 1995, 2003), while not requiring nitrogen fertilizers inputs. However, the approach could be applied to other photosynthetic microorganisms as well.

The cyanobacterium was cultivated in continuous photobioreactors at different incident light intensities with and without additional supply of nitrates, in order to investigate the role of nitrogen, together with light and residence time, on growth kinetics. The experimental results obtained were elaborated to retrieve the value of the specific maintenance rate (Gons and Mur, 1980). The kinetic parameters describing the effect of temperature and the half-saturation constant of nitrogen were instead measured by means of respirometric tests. All these parameters were combined in a comprehensive kinetic model able to describe the biomass growth in autotrophic conditions. The maximum specific growth rate $\mu_{\max }$ could finally be determined by applying the developed kinetic model in the material balances of the continuous reactor, for all the experimental conditions investigated.

\section{MATERIALS AND METHODS}

\section{Experimental Strain and Culture Medium}

The photosynthetic organism used in this work is Anabaena PCC 7122, purchased from the Pasteur Culture Collection of Cyanobacteria, Paris (France). Anabaena PCC 7122, also known as Anabaena cylindrica, is a diazotrophic filamentous cyanobacterium forming heterocysts (i.e., specific cells where the nitrogen fixation is performed) (Fogg, 1944; Allen and Arnon, 1955), and which does not produce toxins (Phillips and Roberts, 1985; Quiblier et al., 2013). This strain was selected as, in preliminary screening tests, it showed good growth and $\mathrm{N}$-fixation performances compared to other diazotrophic species. The cyanobacterium was maintained in $250 \mathrm{~mL}$ Erlenmeyer flasks placed in an orbital shaker, under a continuous light intensity of $75 \mu \mathrm{mol} \mathrm{m} \mathrm{m}^{-2} \mathrm{~s}^{-1}$ and ambient temperature. The culture media used in continuous cultivation experiments were modified BG11 and BG11 (i.e., without nitrogen salts), with a final composition as reported in the Supplementary materials (Table S1). In addition, the media were supplied with $2.5 \mathrm{~g} \mathrm{~L}^{-1}$ of $\mathrm{NaHCO}_{3}$ to obtain a buffered system with the $\mathrm{CO}_{2}$-air gas mixture (section Experimental Setup) and maintain the $\mathrm{pH}$ within the optimal interval of $7.5-8$.

\section{Experimental Setup}

All the experiments were carried out in vertical flat-panel polycarbonate photobioreactors having a working volume $\left(V_{R}\right)$ of $350 \mathrm{~mL}$ and an irradiated surface $\left(A_{P B R}\right)$ of $87.5 \mathrm{~cm}^{2}$. The photobioreactor (PBR) (Figure 1) was specifically designed for the cultivation of this filamentous cyanobacterium. Since it has a high tendency to aggregate and to form clusters, a thickness of $4 \mathrm{~cm}$ was chosen to allow a better stirring of the culture. A thin 

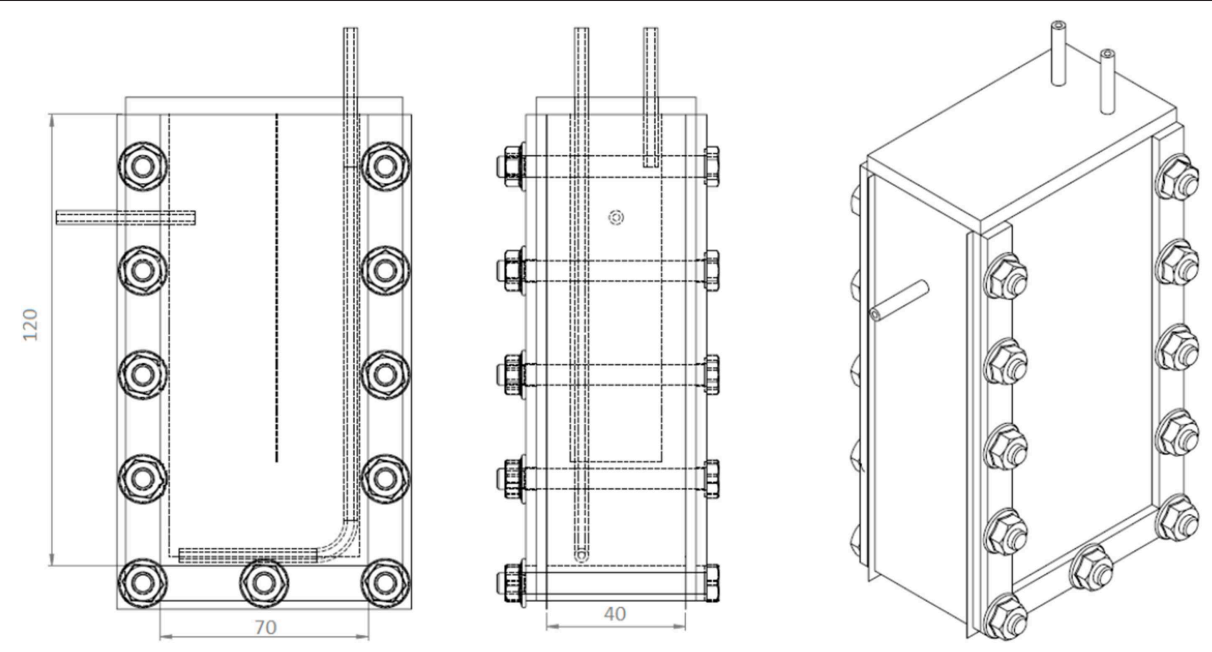

FIGURE 1 | Scheme of the PBR used for the continuous growth experiments. In the first sketch, the dotted vertical line represents the baffle.

baffle was inserted to avoid short-circuiting of the inlet medium flow rate, which was fed from the top.

The mixing was ensured by both a stirring magnet placed at the bottom of the reactor and the bubbling of $\mathrm{CO}_{2}$-enriched air $(5 \% \mathrm{v} / \mathrm{v})$, sparged from the bottom at a flowrate of $1 \mathrm{~L} \mathrm{~h}^{-1}$. The mixing condition was checked by means of tracer experiments, that allow to consider such a reactor as a completely stirred tank one (CSTR) (Sforza et al., 2014a, 2015). Accordingly, the specific growth rate $\mu\left(\mathrm{d}^{-1}\right)$ is equal to the dilution rate $D$, which is the inverse of the residence time $\tau(\mathrm{d})$ according to:

$$
\mu=D=\frac{1}{\tau}
$$

Hence, by changing the residence time, different growth rates can be imposed to the culture.

Fresh inlet BG11 or BG110 was continuously fed by means of a tunable peristaltic pump (120S, Watson Marlow, USA), that allows regulating the inlet flow rate $\mathrm{Q}\left(\mathrm{mL} \mathrm{d}^{-1}\right)$. The reactor volume was kept constant by an overflow tube, from which the biomass was constantly withdrawn. Accordingly, the residence time of the culture inside the PBR was calculated as:

$$
\tau=\frac{V_{R}}{Q}
$$

The temperature was kept constant at $\mathrm{T}=24 \pm 1^{\circ} \mathrm{C}$, in a refrigerated incubator. Continuous artificial white light was provided by a LED lamp (Photon System Instruments, SN-SL 3500-22). The light intensities at the front and back surfaces of the PBR were measured with a photoradiometer (HD 2101.1, Delta Ohm), which quantifies the PAR (Photosynthetically Active Radiation, 400-700 nm).

The reactor was started up in batch operation mode, inoculating the cyanobacterium at initial $\mathrm{OD}_{750}=0.3$ (corresponding to $\sim 0.1 \mathrm{~g} \mathrm{~L}^{-1}$ dry weight). Once a sufficient biomass concentration was reached (about $1 \mathrm{~g} \mathrm{~L}^{-1}$ ) the feed peristaltic pump was switched on. When changing any experimental conditions (i.e., residence time or incident light intensity), a transient period was observed (7-10 d), after which a stable steady-state was reached. For each condition, steady state was maintained for at least 5 days, during which biomass samples were taken twice a day, and the corresponding experimental values were averaged accordingly.

\section{Analytical Procedures and Calculations}

The biomass concentration in the PBR was monitored daily by both optical density at $750 \mathrm{~nm}\left(\mathrm{OD}_{750}\right)$ and dry weight $\left(c_{x}, \mathrm{~g} \mathrm{~L}^{-1}\right)$ measurements. $\mathrm{OD}_{750}$ was measured with a UV-Visible double beam spectrophotometer (UV1900, by Shimadzu, Japan). The dry weight was determined by filtering $10 \mathrm{~mL}$ of culture sample on previously dried $0.45 \mu \mathrm{m}$ nitrocellulose filters. The filters were then dried at $105^{\circ} \mathrm{C}$ in a laboratory oven for at least $2 \mathrm{~h}$. The biomass volumetric and areal productivities were then calculated according to:

$$
P_{x, V}\left(\frac{g}{L \cdot d}\right)=\frac{c_{x}}{\tau}
$$

Once the steady-state was reached, the number of heterocysts was experimentally counted with a Bürker chamber, in order to compare their concentration when the cyanobacterium was grown with or without nitrates feed. Moreover, at steady-state, the experimental values of the specific light supply rate $I_{s p}$ (i.e., the amount of light supplied per unit mass of biomass and unit time) were determined according to:

$$
I_{s p}\left(\frac{m m o l}{g \cdot d}\right)=\frac{I_{0}}{C_{x} W}
$$

where $I_{0}$ is the incident light intensity at the front of the PBR and $W$ is the PBR width $(0.04 \mathrm{~m})$. 


\section{Kinetic Model Description}

According to the result of elemental analysis performed on dried biomass of Anabaena PCC 7122, its chemical formula was determined and, thus, the corresponding autotrophic growth stoichiometry could be written as follows:

$$
\begin{aligned}
0.2518 \mathrm{H}_{2} \mathrm{O} & +0.0202 \mathrm{~N}_{2}+0.2314 \mathrm{CO}_{2} \\
& +0.0018 \mathrm{H}_{2} \mathrm{PO}_{4}^{-}+0.0018 \mathrm{HPO}_{4}^{2-} \\
& \rightarrow \mathrm{C}_{0.2314} \mathrm{H}_{0.5036} \mathrm{O}_{0.2210} \mathrm{~N}_{0.0404} \mathrm{P}_{0.0036} \\
& +0.2513 \mathrm{O}_{2}+0.0054 \mathrm{OH}^{-}
\end{aligned}
$$

According to photosynthesis and nitrogen-fixation processes, water, atmospheric nitrogen, carbon dioxide and phosphates are consumed to produce new biomass and release oxygen.

The equation describing the autotrophic microalgal growth rate $\left(r_{x}, \mathrm{~g} \mathrm{~L}^{-1} \mathrm{~d}^{-1}\right)$ can be written as a function of biomass concentration $\left(c_{x}, \mathrm{~g} \mathrm{~L}^{-1}\right)$, the maximum specific growth rate $\left(\mu_{\max }, \mathrm{d}^{-1}\right)$, temperature $(\Phi(T))$, specific light $\left(f\left(I_{s p}\right)\right)$ and the most limiting nutrient that, in this case, is nitrogen $(f(N))$. Moreover, the kinetic model takes into account the specific maintenance rate $\left(\mu_{e}\right)$, i.e., the loss of biomass due to turnover of cellular components and cell repair, which represents a negative term, thus reducing the net biomass growth rate, according to Equation (5):

$$
r_{x}=c_{x} \cdot \mu_{\max } \cdot \Phi(T) \cdot f(N) \cdot f\left(I_{s p}\right)-\mu_{e} \cdot c_{x}
$$

The term accounting for the effect of temperature was calculated according to the model proposed by Bernard et al. (2015) based on the so-called cardinal temperature model with inflection (CTMI) (Rosso et al., 1993):

$$
\mu(T)= \begin{cases}0 & \text { for } T<T_{\min } \\ \mu_{o p t} \cdot \Phi(T) & \text { for } T_{\min }<T<T_{\max } \\ 0 & \text { for } T>T_{\max }\end{cases}
$$

where

$$
\Phi(T)=\frac{\left(T-T_{\max }\right)\left(T-T_{\min }\right)^{2}}{\left(T_{o p t}-T_{\min }\right)\left[\left(T_{o p t}-T_{\min }\right)\left(T-T_{o p t}\right)\right.}
$$

The function $\Phi(T)$ includes three parameters with a physical meaning: $T_{\min }, T_{\max }$ and $T_{o p t}\left({ }^{\circ} \mathrm{C}\right) . T_{\min }$ and $T_{\max }$ are the temperatures below and above which there is no growth nor respiration, while $T_{o p t}$ is the temperature at which the growth rate is maximum. In this way, $\mu(T)$ assumes a typical bellshaped profile.

The term accounting for the limitation due to the nitrogen concentration $\left(c_{N}\right)$ was represented as a Monod function (Monod, 1949):

$$
f(N)=\frac{c_{N}}{K_{N}+c_{N}}
$$

where $K_{N}$ is the half-saturation constant $\left(\mathrm{mg}_{N} \mathrm{~L}^{-1}\right)$.
The term accounting for the effect of light was modeled according to Haldane (1930), in order to consider both the saturation and photoinhibition effects:

$$
f\left(I_{s p}\right)=\frac{I_{s p}}{K_{L}+I_{s p}+\frac{I_{s p}^{2}}{K_{I}}}
$$

$K_{L}$ and $K_{I}$ are the half-saturation and the inhibition constants (mmol photons $\mathrm{g}^{-1} \mathrm{~d}^{-1}$ ) of light, respectively, expressed in terms of specific light supply rate $\left(I_{s p}\right.$, mmol photons $\left.\mathrm{g}^{-1} \mathrm{~d}^{-1}\right)$ in order to account for self-shading effects due to increasing biomass concentration, according to Equation (4).

The specific maintenance rate $\left(\mu_{e}\right)$, which was first described for heterotrophic microorganisms by Pirt (1965) as "the energy consumed for functions other than productions of new cell material," was calculated according to the model proposed by Gons and Mur (1980). These authors observed that growth yields decrease at low growth rates as a consequence of a requirement of energy for maintenance of existing cells. Therefore, the growth rate is proportional to the energy absorbed, with the exception of the energy required for the cell maintenance. According to these considerations and to the energy balance, they derived the following equation:

$$
\mu=\left(\frac{d E}{d t} \cdot \frac{1}{X}\right) \cdot c-\mu_{e}
$$

where $\frac{d E}{d t}$ is the light energy uptake rate $\left(\mathrm{J} \mathrm{d}^{-1}\right), X$ is the energy stored in the culture biomass $(\mathrm{J})$, and $c$ is the "true" efficiency of light conversion into the chemical energy that is stored in biomass (dimensionless). Gons and Mur (1980) applied the model to the continuous light-limited growth of Scenedesmus protuberans and found a linear dependence of the growth rate on the specific light uptake rate $\left(\frac{d E}{d t} \cdot \frac{1}{X}\right)$. Hence, by correlating their data according to Equation (10), they derived $c$ and $\mu_{e}$ values.

In our case, the specific light uptake rate $\frac{d E}{d t} \cdot \frac{1}{X}\left(\mathrm{~d}^{-1}\right)$, which represents the amount of light energy utilized per unit of biomass over time, was hence calculated from the experiments according to:

$$
\frac{d E}{d t} \cdot \frac{1}{X}=\frac{I_{a b s} \cdot E_{p} \cdot A_{P B R}}{c_{x} \cdot L H V \cdot V_{R}}
$$

where $I_{a b s}$ is the absorbed photon flux density, calculated by subtracting the irradiance at the back of the PBR from the incident light intensity ( $\mu \mathrm{mol}$ photons $\mathrm{m}^{-2} \mathrm{~s}^{-1}$ ), $E_{p}$ is the average energy of a photon (assumed to be $0.223 \mathrm{~kJ} / \mathrm{mmol}$ ), $A_{P B R}$ is the illuminated surface of the $\operatorname{PBR}\left(\mathrm{m}^{2}\right), L H V$ is the lower heating value of the biomass (assumed to be equal to $18.66 \mathrm{~kJ} / \mathrm{g}$ Zaimes and Khanna, 2013) and $V_{R}$ is the PBR volume $\left(\mathrm{m}^{3}\right)$.

\section{Respirometric Tests}

In order to retrieve the values of the parameters contained in Equations (7-9), respirometric tests were carried out. The experimental apparatus and protocol used were the same described by Sforza et al. (2019). 
This technique has already been used to determine kinetic parameters of microalgae growth by Decostere et al. (2013) and to evaluate microalgal performances in wastewater by Rossi et al. (2018). The protocol is based on the measurement of oxygen production or consumption due to the growth and respiration of microalgal biomass, to which it is correlated trough yields factors:

$$
Y_{O_{2} / x}=\frac{\frac{d c_{O_{2}}}{d t}}{\frac{d c_{x}}{d t}}=\frac{O P R}{r_{x}}
$$

where $Y_{O_{2} / x}$ is the oxygen/biomass yield and $O P R$ is the oxygen production rate $\left(\mathrm{mgO}_{2} \mathrm{~L}^{-1} \mathrm{~d}^{-1}\right)$. It follows that the normalized oxygen production rate $\left(O P R_{s p}=O P R / c_{x}\right)$ is:

$$
\frac{O P R}{c_{x}}=\mu_{\max } \cdot \Phi(T) \cdot f(N) \cdot f\left(I_{s p}\right) \cdot Y_{O_{2} / x}-\mu_{e} \cdot Y_{O_{2} / x}
$$

Each respirometric test started by preparing a cyanobacterium inoculum of about $0.2 \mathrm{~g} \mathrm{~L}^{-1}$ of DW. After having filled a flask with it, the inoculum was exposed to light-dark cycles of 5:5 min each, obtained by means of a digital controller connected to a LED lamp. The concentration of nitrogen (supplied as sodium nitrate) or the experimental conditions (light intensity and temperature) were varied independently to study the effect of these variables on the growth. Each test lasted about $3 \mathrm{~h}$ and resulted in dissolved oxygen (DO) concentration profiles along with time. During light phases, a positive increase of DO is measured (i.e. OPR), while a negative one is observed during dark phases (i.e., OCR, oxygen consumption rate).

Experimental DO data, obtained from the oximeter (HD2109.1 DELTA OHM), were corrected by taking into account the occurrence of oxygen mass transfer with the atmosphere and, then, fitted by a straight line.

$$
\frac{d C_{O_{2}}}{d t}=k_{L} a\left(C_{O_{2}}^{*}-C_{O_{2}}\right)+O P R
$$

Where $\frac{d \mathrm{C}_{2}}{d t}$ is the time derivative of $\mathrm{DO}$ concentration $\left(\mathrm{mg}_{\mathrm{O} 2}\right.$ $\mathrm{L}^{-1} \mathrm{~d}^{-1}$ ) that corresponds to the slope of the straight line, $k_{L} a$ is the global oxygen mass transfer coefficient that was determined experimentally by Sforza et al. (2019) and is equal to 0.0033 $\mathrm{min}^{-1}, \mathrm{C}_{\mathrm{O}_{2}}^{*}$ is the oxygen saturation concentration in the liquid $\left(\mathrm{mgO}_{2} \mathrm{~L}^{-1}\right)$ and $\mathrm{C}_{\mathrm{O}_{2}}$ is the $\mathrm{DO}$ concentration $\left(\mathrm{mg}_{\mathrm{O} 2} \mathrm{~L}^{-1}\right)$.

At least four measurements were performed and averaged to obtain the OPR value of each condition (i.e., four darklight cycles of $5: 5 \mathrm{~min}$ each). The specific $\mathrm{OPR}_{\mathrm{sp}}$ and $\mathrm{OCR}_{\mathrm{sp}}$ $\left(\mathrm{mg}_{\mathrm{O} 2} \mathrm{mg}_{\mathrm{X}}^{-1} \mathrm{~d}^{-1}\right)$ were then obtained by normalization of OPR and OCR (mgo2 $\mathrm{L}^{-1} \mathrm{~d}^{-1}$ ) with respect to the initial biomass concentration measured as dry weight $\left(\mathrm{mgX}^{-1}\right)$.

The value of $\mathrm{OPR}_{\mathrm{sp}}$ obtained during the light phase represents a net oxygen production rate, because it includes the oxygen consumption, which still occurs even under light exposure. This consumption represents energy loss that is used for maintenance of biological functions, which is mathematically described by the specific rate of maintenance energy $\mu_{e}$ (Equation 5). Accordingly, by summing the absolute values of $\mathrm{OCR}_{\mathrm{sp}}$ to $\mathrm{OPR}_{\mathrm{sp}}$, the actual photosynthetic growth is obtained. Mathematically, this translates to:

$$
\frac{O P R}{c_{x}}+\left|\frac{O C R}{c_{x}}\right|=\mu_{\max } \cdot \Phi(T) \cdot f(N) \cdot f\left(I_{s p}\right) \cdot Y_{O_{2} / x}
$$

The experiments were performed so that all the operating conditions, except one, were set to their optimal values. In this way, it is possible to study the effect of a single variable. For example, to study the effect of the nitrogen concentration, temperature and light intensities were set to their optimal values and Equation (15) became:

$$
\frac{O P R}{c_{x}}+\left|\frac{O C R}{c_{x}}\right|=\left(\mu_{\max } \cdot Y_{O_{2} / x}\right) \cdot \frac{c_{N}}{K_{N}+c_{N}}
$$

The same is valid when studying the effects of temperature and light. In these cases, nitrogen was supplied in a nonlimiting concentration.

\section{$\mu_{\max }$ Estimation}

The respirometric tests allowed to evaluate all the parameters included in Equations (7-9) $\left(K_{N}, K_{L}, K_{I}, T_{\min }, T_{o p t}, T_{\max }\right)$, whereas elaborating the experimental data obtained from continuous cultivation with the model of Gons and Mur (1980) allowed to calculate the value of $\mu_{e}$. Therefore, $\mu_{\max }$ is the only unknown kinetic parameter in Equation (6) that needs to be estimated.

From the material balance of a CSTR:

$$
\frac{d c_{x}}{d t}=\frac{c_{x, i n}}{\tau}-\frac{c_{x}}{\tau}+r_{x}
$$

at steady state $\left(\frac{d c_{x}}{d t}=0\right)$ and with null inlet biomass concentration, $r_{x}$ can be calculated by simply dividing the steadystate biomass concentration measured experimentally by the residence time $(\tau)$ :

$$
r_{x}=\frac{c_{x}}{\tau}
$$

By equaling Equation (18) with Equation (5), i.e., comparing the values of $r_{x}$ obtained at the different experimental conditions with the kinetic model, the only unknown variable is $\mu_{\max }$, which can hence be calculated as:

$$
\mu_{\max }=\frac{1+\mu_{e} \cdot \tau}{\tau \cdot \phi(T) \cdot \frac{c_{N}}{K_{N}+c_{N}} \cdot \frac{I_{s p}^{\exp }}{I_{s p}^{\exp }+K_{L}+\frac{\left(I_{s p}^{\exp }\right)^{2}}{K_{I}}}}
$$

where $c_{N}$ is the experimental concentration of nitrogen $\left(\mathrm{mg}_{\mathrm{N}} \mathrm{L}^{-1}\right)$.

\section{Statistical Significance}

$T$-student tests were applied to ascertain statistical differences in biomass concentration and productivity obtained under cultivation in BG11 and $\mathrm{BG} 11_{0}$. The level of statistical significance was assumed for $p$-value $<0.05$. 


\section{RESULTS AND DISCUSSION Continuous Cultivation}

Continuous experiments were carried out to assess the effect of operating variables on biomass productivity. The effect of residence time, which is the main operating variable in continuous photobioreactors, was investigated ( $\tau=1-4.6 \mathrm{~d}$ ), under constant light intensities of $190 \mu \mathrm{mol} \mathrm{m} \mathrm{m}^{-2} \mathrm{~s}^{-1}$ and of $650 \mu \mathrm{mol} \mathrm{m} \mathrm{m}^{-2} \mathrm{~s}^{-1}$, by feeding BG11 0 medium, i.e., with no nitrogen salts. In addition, Anabaena was also cultivated under a constant light intensity of $650 \mu \mathrm{mol} \mathrm{m} \mathrm{m}^{-2} \mathrm{~s}^{-1}$ by feeding BG11 medium with $3 \mathrm{~g} \mathrm{~L}^{-1}$ of sodium nitrate, in order to verify if the concentration of atmospheric nitrogen dissolved in the liquid, determined by its solubility, was limiting the growth of the cyanobacterium.

Figure 2 reports the average biomass concentration $\left(\mathrm{g} \mathrm{L}^{-1}\right)$ obtained at steady-state for each value of residence time at different irradiances and medium fed. It can be seen that it increased along with the residence time, as expected. However, the observed trend is not linear, and it tends to flatten at high residence times as a consequence of self-shading effects between cells (Janssen et al., 2003; Sforza et al., 2014b). Moreover, a higher incident light intensity resulted in an increased biomass concentration, suggesting that, at $190 \mu \mathrm{mol} \mathrm{m}^{-2} \mathrm{~s}^{-1}$, the growth of Anabaena was limited by light.

The comparison between biomass concentrations obtained when supplying nitrates with respect to the ones obtained under strictly nitrogen-fixing conditions highlights that both optical density and dry weight are slightly higher in the case of biomass cultivated in presence of $3 \mathrm{~g} \mathrm{~L}^{-1}$ of sodium nitrate. However, the difference is not considerable, except for the higher residence time. This suggests that Anabaena's growth is not

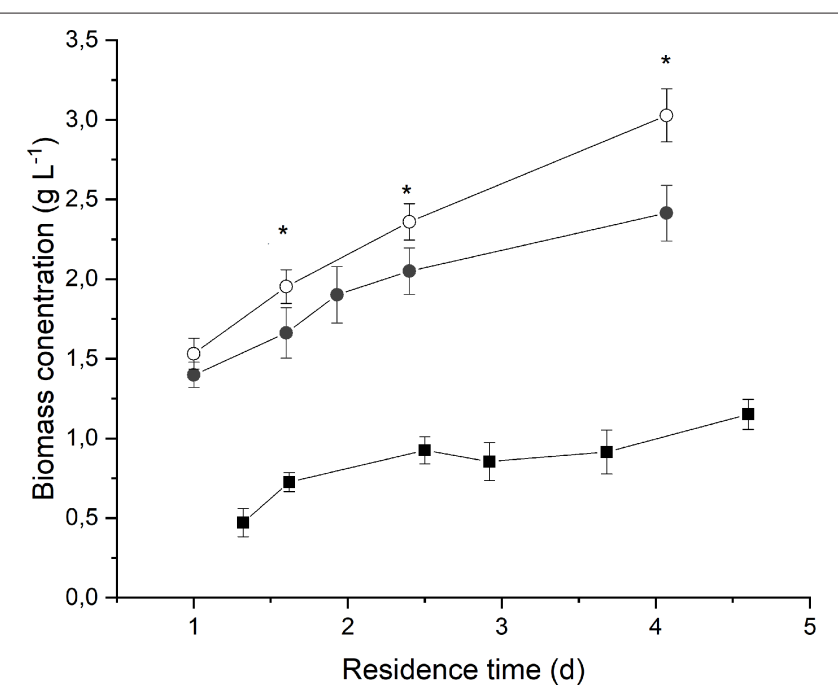

FIGURE 2 | Biomass concentration as a function of residence time at 190 $\mu \mathrm{mol} \mathrm{m} \mathrm{m}^{-2} \mathrm{~s}^{-1}$ and BG110 medium (full squares) $650 \mu \mathrm{mol} \mathrm{m}-2 \mathrm{~s}^{-1}$ and BG11。 medium (full circles), and $650 \mu \mathrm{mol} \mathrm{m}^{-2} \mathrm{~s}^{-1}$ and BG11 medium (open circles). Asterisks mark statistically different results between cultivation in BG11 and BG110. significantly limited by nitrogen concentration or uptake even under atmospheric nitrogen-fixing conditions.

By comparing the heterocysts concentration (number of cells per $\mu \mathrm{g}$ of dry weight) in the reactors irradiated at $650 \mu \mathrm{mol} \mathrm{m}^{-2}$ $\mathrm{s}^{-1}$ as expected, the value resulted higher in the case of biomass cultivated in nitrogen-fixation conditions, for all the residence times studied (Figure S1). However, the presence of heterocysts was noticed also in the case of biomass cultivated with a directly available nitrogen source $\left(\mathrm{NaNO}_{3}\right)$ in the culture medium.

By observing Figure 3 it is evident that biomass volumetric productivity increased if the residence time decreased, so that simultaneously the biomass growth rate increased. It is widely acknowledged that when considering continuous autotrophic cultivation of photosynthetic microorganisms in a chemostat reactor, the biomass productivity profile shows a maximum in correspondence of the optimal value of residence time. On the right-hand side, the biomass growth is limited by self-shading effect along the reactor depth; on the left-hand side, when increasing the volumetric flow rate, the biomass removal from the reactor overcomes the biomass growth until the wash-out residence time is reached (Moreno et al., 2003; Takache et al., 2010; Barbera et al., 2015). Clearly, the optimum operating residence time depends on the incident irradiance, and should be assessed accordingly. In fact, in the case of an incident light intensity equal to $190 \mu \mathrm{mol} \mathrm{m} \mathrm{m}^{-2} \mathrm{~s}^{-1}$, the maximum of productivity $\left(0.45 \pm 0.04 \mathrm{~g} \mathrm{~L}^{-1} \mathrm{~d}^{-1}\right)$ was reached for a residence time of about $1.6 \mathrm{~d}$. Instead, at $650 \mu \mathrm{mol} \mathrm{m} \mathrm{m}^{-2} \mathrm{~s}^{-1}$ the maximum was not reached even if the residence time was decreased down to $1 \mathrm{~d}$, suggesting that an even higher biomass growth rate could have been applied. However, a remarkable value of volumetric biomass productivity $\left(1.4 \pm 0.1 \mathrm{~g} \mathrm{~L}^{-1} \mathrm{~d}^{-1}\right)$ was found at $1 \mathrm{~d}$ of residence time when irradiating the photobioreactor with 650 $\mu \mathrm{mol} \mathrm{m} \mathrm{m}^{-2} \mathrm{~s}^{-1}$. Reported productivity values of Anabaena ATCC 33047 obtained under outdoor cultivation conditions range from $0.06 \mathrm{~g} \mathrm{~L}^{-1} \mathrm{~d}^{-1}$ in the winter to $0.13 \mathrm{~g} \mathrm{~L}^{-1} \mathrm{~d}^{-1}$ in the summer season (Moreno et al., 2003).

\section{Maintenance Energy}

The evaluation of the maintenance energy requirement in Anabaena PCC 7122 was obtained based on the elaboration of experimental data of continuous cultivation at low incident light $\left(I_{\text {in }}=190 \mu \mathrm{mol} \mathrm{m} \mathrm{m}^{-2} \mathrm{~s}^{-1}\right)$ as well as at high light $\left(I_{\text {in }}=650\right.$ $\mu \mathrm{mol} \mathrm{m}{ }^{-2} \mathrm{~s}^{-1}$ ), both for the growth in presence of nitrates and not, according to the model described in section Kinetic Model Description. The results are reported in Figure 4.

Each data set was fitted according to Equation (10) to obtain the values of the "true" efficiency of light conversion into the chemical energy stored in biomass (c) (i.e., the slope of the straight line) and the specific maintenance energy (i.e., the intercept). The values of the regressed parameters and the quality of the fitting are summarized in Table $\mathbf{1}$.

The results obtained are comparable to the values reported by Gons and Mur (1980). In fact, they obtained a value of $c$ that varies between 0.11 and 0.13 , which is very similar to our values $(0.14-0.16)$.

On the other hand, by observing the values of $\mu_{E}$, it can be seen that a higher incident light intensity corresponded to 


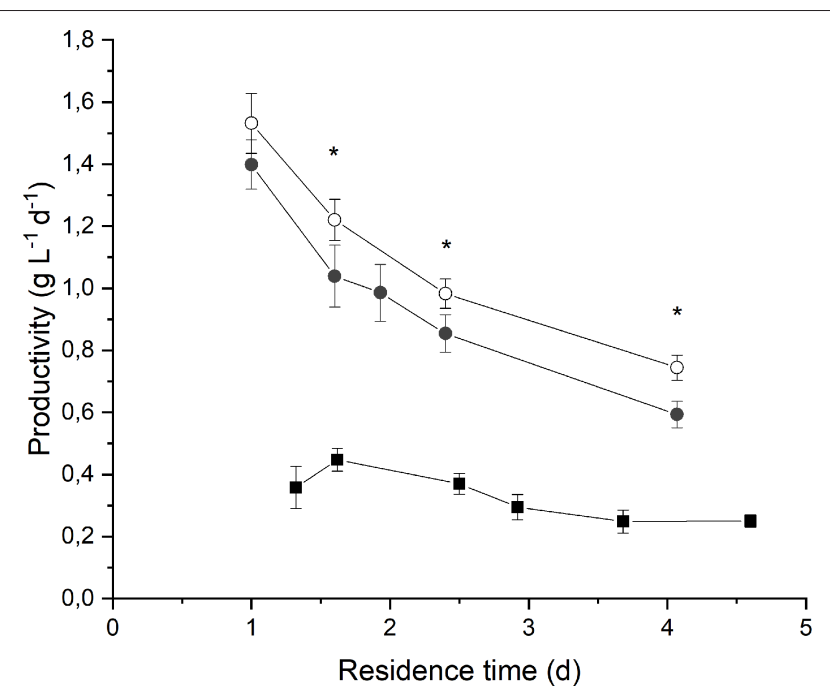

FIGURE 3 | Biomass volumetric productivity as a function of residence time at $190 \mu \mathrm{mol} \mathrm{m} \mathrm{m}^{-2} \mathrm{~s}^{-1}$ and BG11。 medium (full squares) $650 \mu \mathrm{mol} \mathrm{m}^{-2} \mathrm{~s}^{-1}$ and BG110 medium (full circles), and $650 \mu \mathrm{mol} \mathrm{m} \mathrm{m}^{-2} \mathrm{~s}^{-1}$ and BG11 medium (open circles). Asterisks mark statistically different results between cultivation in BG11 and BG110.

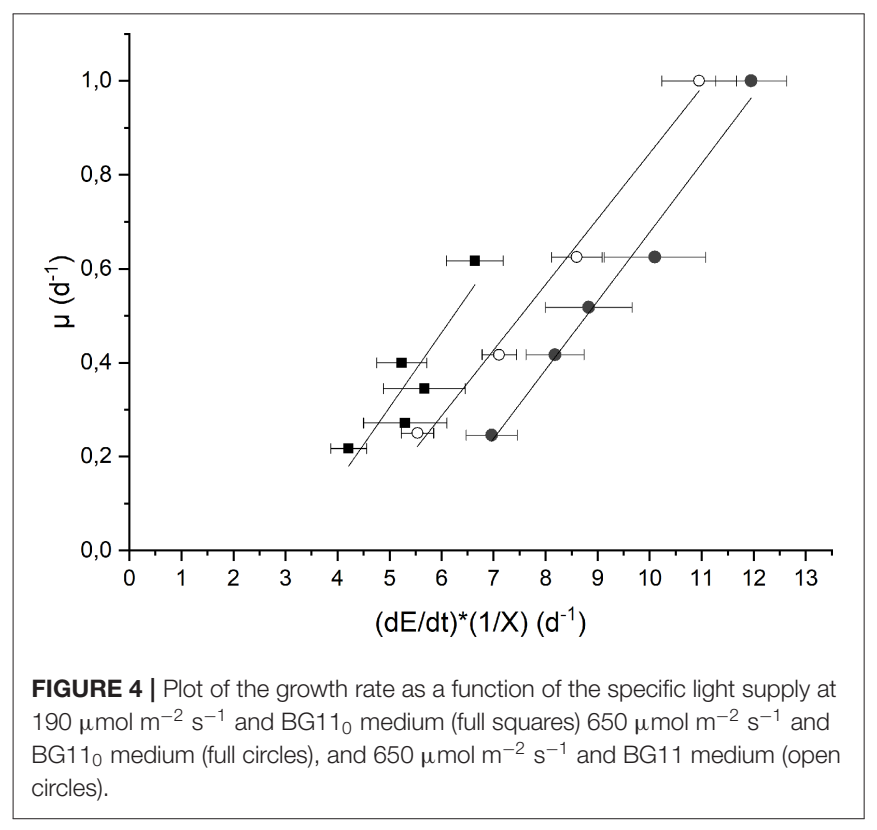

a higher value of specific maintenance rate. For the biomass cultivated in BG11 $1_{0}$, a value of $0.49 \mathrm{~d}^{-1}$ corresponded to the low incident light of $190 \mu \mathrm{mol} \mathrm{m}^{-2} \mathrm{~s}^{-1}$, whereas $0.79 \mathrm{~d}^{-1}$ to the higher one $\left(650 \mu \mathrm{mol} \mathrm{m}^{-2} \mathrm{~s}^{-1}\right)$. This suggests that, at $650 \mu \mathrm{mol}$ $\mathrm{m}^{-2} \mathrm{~s}^{-1}$, a large part of energy was diverted from the biomass growth to cell repair, possibly due to photoinhibition phenomena (Kliphuis et al., 2012).

In addition, it appears that at high light intensity $(650 \mu \mathrm{mol}$ $\mathrm{m}^{-2} \mathrm{~s}^{-1}$ ), the specific maintenance rate was slightly lower for the biomass cultivated in presence of sodium nitrate. This is
TABLE 1 | Parameters of linearization of data reported in Figure 4, according to Equation (10).

\begin{tabular}{|c|c|c|c|c|}
\hline & $I_{o}\left(\mu \mathrm{mol} \mathrm{m}{ }^{-2} \mathrm{~s}^{-1}\right)$ & $c(-)$ & $\mu_{E}\left(\mathrm{~d}^{-1}\right)$ & $R^{2}$ \\
\hline \multirow[t]{2}{*}{$\mathrm{BG} 11_{0}$} & 190 & $0.16 \pm 0.04$ & $0.49 \pm 0.24$ & 0.81 \\
\hline & 650 & $0.15 \pm 0.01$ & $0.79 \pm 0.11$ & 0.98 \\
\hline BG11 & 650 & $0.14 \pm 0.01$ & $0.55 \pm 0.07$ & 0.99 \\
\hline
\end{tabular}

reasonable because the process of atmospheric nitrogen fixation is undoubtedly energy demanding.

Summarizing, our results suggest that irradiation intensity affects the value of the maintenance rate $\mu_{E}$, according to what already observed also for the microalgae Scenedesmus obliquus by Sforza et al. (2015). In particular, $\mu_{E}$ was observed to be strongly increased under inhibiting irradiation. On the contrary, Gons and Mur (1980) found a $\mu_{E}$ independent from the incident light intensity used. However, this can be explained by considering that these authors performed all the experiments at irradiances below the inhibiting value. In fact, other authors (Kliphuis et al., 2012) found that higher light intensities resulted in lower biomass/light yields, suggesting that indeed a larger portion of the incident light was "wasted."

\section{Results of Respirometric Tests}

A series of respirometric tests were performed with the aim of retrieving the kinetic parameters to describe the growth of Anabaena PCC 7122 in autotrophic conditions. In the following sections, the results obtained for the light, temperature and nitrogen effects are reported and discussed.

\section{Light Effect}

The effect of light on growth kinetics was investigated, since it is the main source of energy, essential to support metabolism in autotrophic conditions (Yun and Park, 2003).

The incident light intensity was changed every 4 light-dark cycles and progressively set to values of $50,75,100,150,450$, and $730 \mu \mathrm{mol} \mathrm{m}^{-2} \mathrm{~s}^{-1}$.

Respirometric tests were carried out with two different preinocula: one adapted to a low incident light of $150 \mu \mathrm{mol}$ $\mathrm{m}^{-2} \mathrm{~s}^{-1}$, the other adapted to a high incident light of 650 $\mu \mathrm{mol} \mathrm{m}{ }^{-2} \mathrm{~s}^{-1}$. The results obtained experimentally were plotted as a function of the specific light supply rate $\left(I_{s p}\right)$ and then fitted with the Haldane model (Equation 9). Figure 5 shows the experimental data together with the fitting curves for the low light-adapted preincoulum (the high light-adapted one showed a similar trend). As it can be observed, the biomass growth rate, which is correlated to the sum of oxygen production and consumption rates (Equation 15), increased with increasing values of $I_{s p}$ up to a maximum value, and then decreased due to inhibition effects.

The quality of fitting is good and the obtained model parameters together with their standard deviations are summarized in Table 2. It can be observed that the values of the half-saturation and inhibition constants are very similar in the two cases, suggesting the reliability of the proposed protocol 


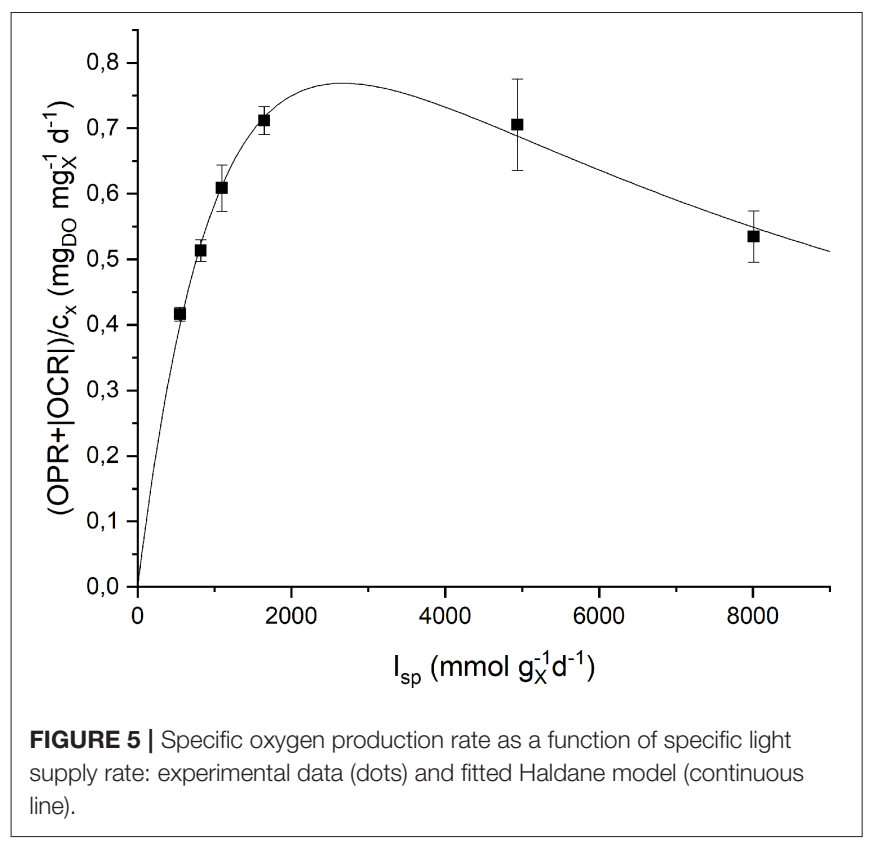

TABLE 2 | Summary of the fitted parameters of the Haldane model.

\begin{tabular}{lll}
\hline Adaptation & $\boldsymbol{K}_{\mathbf{L}}\left(\mathbf{m m o l}\right.$ photons $\left.\mathbf{g}_{\mathbf{x}}^{-\mathbf{1}} \mathbf{d}^{\mathbf{- 1}}\right)$ & $\boldsymbol{K}_{\mathbf{L}}\left(\mathbf{m m o l}\right.$ photons $\left.\mathbf{g}_{\mathbf{x}}^{-\mathbf{1}} \mathbf{d}^{\mathbf{- 1}}\right)$ \\
\hline Low light & $2,023 \pm 515$ & $3,531 \pm 958$ \\
High light & $2,192 \pm 575$ & $3,730 \pm 1,295$ \\
\hline
\end{tabular}

to assess the effect of light intensity on the growth kinetics, regardless the previous inoculum acclimation.

\section{Temperature Effect}

Besides light intensity, temperature is the most important factor influencing the microorganism growth in autotrophic and nutrient unlimited conditions (Bernard and Rémond, 2012).

To study the effect of temperature on the biomass growth, all the other nutrients were supplied in excess, and the light intensity was set to its optimal value, according to the previous results. The investigated values of temperature, changed every 4 light-dark cycles, were: $18,24,28,31$, and $35^{\circ} \mathrm{C}$. The temperature value was increased progressively by heating up the water bath. The values of $T_{o p t}, T_{\min }$ and $T_{\max }$ were hence fitted according to the model by Bernard and Rémond (2012) (Equation 8). Figure 6 shows the experimental data and the fitting curve.

As expected, according to Bernard and Rémond (2012), the biomass growth rate is null below $T_{\min }$ and above $T_{\max }$, and reaches its maximum value when the temperature is equal to $T_{o p t}$. In particular, for $T>T_{\text {otp }}$, the growth rate rapidly decreases because of the heat stress that can affect activities of enzymes (denaturation, inactivation) or modify proteins involved in photosynthesis (Ras et al., 2013).

Moreover, it can be observed that the model (the one represented in Figure 6 by the solid line) can represent well the experimental points. The model parameters obtained from the fitting procedure together with the standard deviations

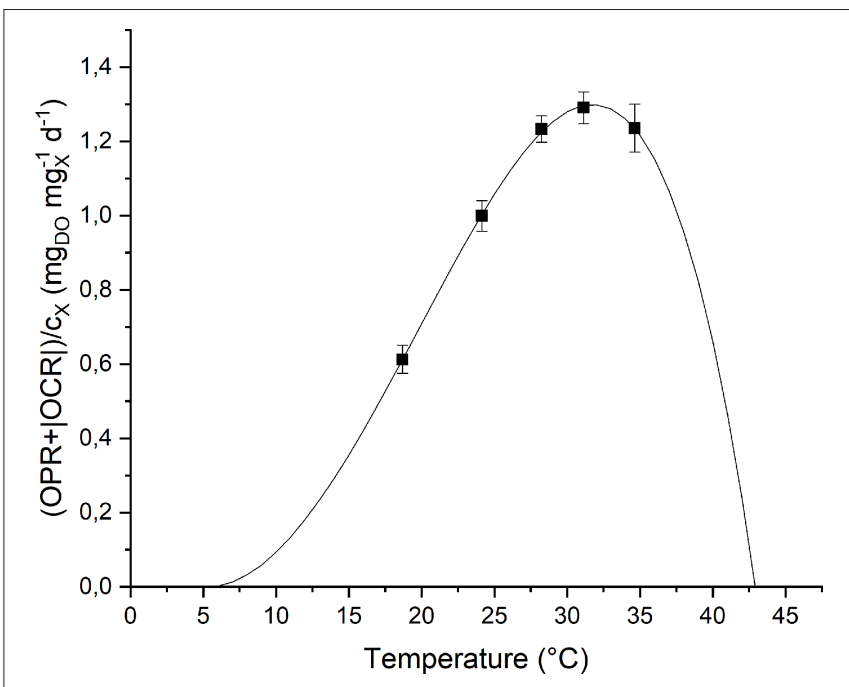

FIGURE 6 | Specific oxygen production rate as a function of temperature: experimental data (dots) and fitted model (continuous line).

TABLE 3 | Summary of the fitted parameters of the temperature model.

\begin{tabular}{lll}
\hline $\boldsymbol{T}_{\text {opt }}\left({ }^{\circ} \mathbf{C}\right)$ & $\boldsymbol{T}_{\min }\left({ }^{\circ} \mathbf{C}\right)$ & $\mathbf{T}_{\max }\left({ }^{\circ} \mathbf{C}\right)$ \\
\hline $31.74 \pm 0.13$ & $5.29 \pm 1.23$ & $42.93 \pm 1.19$ \\
\hline
\end{tabular}

are summarized in Table 3. The value found for $T_{o p t}$ is comparable to those reported in literature for microalgae: 20$30^{\circ} \mathrm{C}$ (Rinanti, 2016).

\section{Nitrogen Effect}

Since Anabaena PCC 7122 is a nitrogen-fixing cyanobacterium, it is interesting to study its growth in nitrogen limited conditions, in order to determine whether the concentration of atmospheric nitrogen dissolved in the liquid, as supplied in continuous cultivation by means of bubbling $\mathrm{CO}_{2}$-enriched air, is sufficient or limiting, and to which extent.

The values of nitrogen concentration studied, supplied as sodium nitrate and changed every 4 light-dark cycles, were: 0 , $2,6,8$, and $15 \mathrm{mg} \mathrm{L}^{-1}$. The change in nitrates concentration was obtained by progressive addition of $\mathrm{NaNO}_{3}$ in the sealed flask. Since Anabaena is not only capable of using nitrogen in nitrate form, but also atmospheric nitrogen, before each addition of $\mathrm{NaNO}_{3}$, the biomass sample was bubbled with argon in order to strip the dissolved atmospheric nitrogen which could alter the microorganism response to the nutrient supply.

By analyzing the normalized OPR and OCR obtained at each nitrogen concentration (Figure S2) it could be noticed that they display a similar trend, since both of them increase (in absolute value) at increasing nitrogen concentration. Moreover, even at $0 \mathrm{mg} \mathrm{L}^{-1}$ of $\mathrm{N}$ and after stripping with argon, a small rate of oxygen production was detected. This can be explained considering the basal photosynthetic activity of cells: nongrowing cells are responsible of a short-term oxygen production rate enhanced by the previous exposure of the preinoculum 


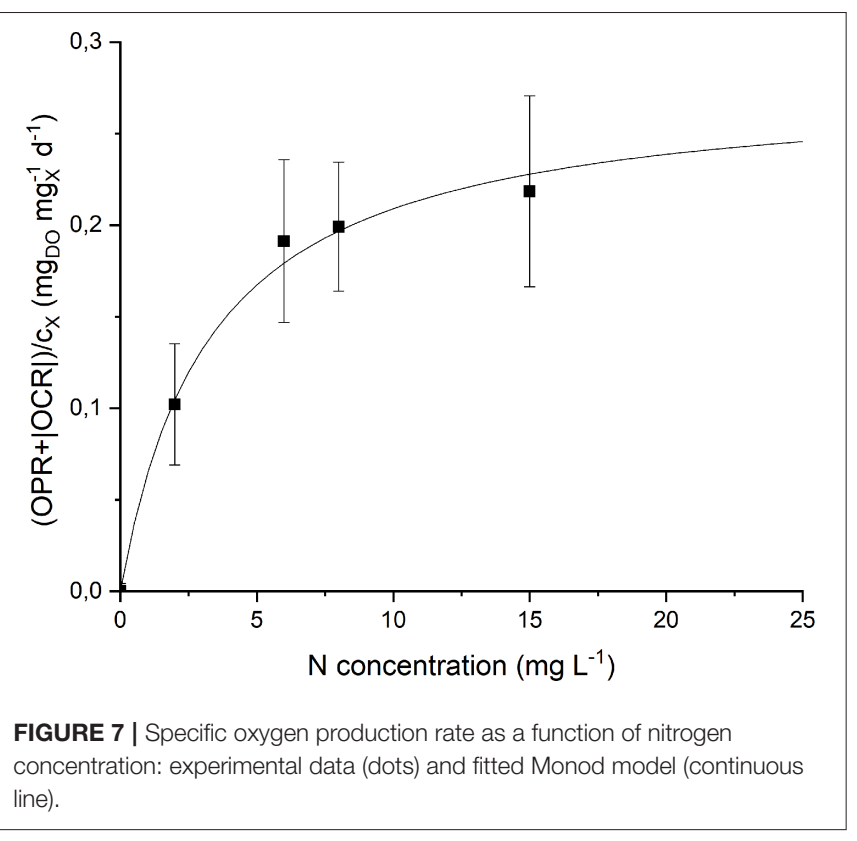

to light. This phenomenon was taken into account through a further normalization of the data, subtracting the value of $\left(\frac{O P R}{c_{x}}+\frac{|O C R|}{c_{x}}\right)$ obtained at $0 \mathrm{mg} \mathrm{L}^{-1}$ of $\mathrm{N}$ from all the other experimental points. Figure 7 shows the experimental results together with the fitted Monod model (Equation 9). The value of the half-saturation constant obtained from the regression resulted equal to $2.90 \pm 0.67 \mathrm{mgN}^{-1}$.

Note that the obtained value of $K_{N}$ is much lower than typical values of nitrogen half-saturation constant reported in literature for green microalgae. For example, some authors measured a value of $19.4 \mathrm{mg} \mathrm{L}^{-1}$ (Rowley, 2010) and $23.4 \mathrm{mg} \mathrm{L}^{-1}$ (Ramos Tercero et al., 2014) for the green microalga Chlorella protothecoides. However, specific studies about cyanobacteria confirm the value obtained in our work. Cornet et al. (1992) found a half-saturation constant of $1.2 \mathrm{mg} \mathrm{L}^{-1}$ for Spirulina platensis, Halterman and Toetz (1984) found a value close to $0 \mathrm{mg}$ $\mathrm{L}^{-1}$ for Anabaena A7214, while Hattori (1962) reported $0.98 \mathrm{mg}$ $\mathrm{L}^{-1}$ for Anabaena cylindrica. This is also reasonable considering that nitrogen-fixing organisms should be adapted to the low dissolved nitrogen concentration given by the solubility of this gas in the liquid medium $\left(\sim 13 \mathrm{mg} \mathrm{L}^{-1}\right)$. In this way, the supply of nitrates at higher concentrations (greater than the saturation one) does not result in improved biomass production rate, as confirmed by the results of our continuous experiments (section Continuous Cultivation).

\section{Maximum Specific Growth Rate $\mu_{\max }$}

Based on the methodology described in section 2.6, once all the kinetic parameters were determined according to the results presented, the maximum specific growth rate was calculated for each experimental condition investigated. The values obtained for each steady state of the continuous cultivation experiments
TABLE $4 \mid \mu_{\max }$ determination results.

\begin{tabular}{|c|c|c|c|}
\hline Light $\left(\mu \mathrm{mol} \mathrm{m} \mathrm{m}^{-2} \mathrm{~s}^{-1}\right)$ & $\tau(\mathrm{d})$ & $c_{x}^{\exp }\left(g L^{-1}\right)$ & $\mu_{\max }\left(\mathrm{d}^{-1}\right)$ \\
\hline 190 & 1.32 & 0.47 & 7.49 \\
\hline 190 & 1.62 & 0.73 & 8.82 \\
\hline 190 & 2.5 & 0.93 & 8.51 \\
\hline 190 & 2.92 & 0.86 & 7.48 \\
\hline 190 & 3.68 & 0.91 & 7.22 \\
\hline 190 & 4.6 & 1.15 & 8.09 \\
\hline 650 & 4.1 & 2.41 & 7.95 \\
\hline 650 & 2.4 & 2.05 & 8.24 \\
\hline 650 & 1.9 & 1.90 & 8.50 \\
\hline 650 & 1.6 & 1.66 & 8.42 \\
\hline 650 & 1.0 & 1.40 & 9.66 \\
\hline
\end{tabular}

is reported in Table 4. The average $\mu_{\max }$ resulted equal to $8.22 \pm 0.69 \mathrm{~d}^{-1}$.

The value obtained according to the methodology proposed here appeared slightly higher than what is usually found in the literature, where values around $2.8-3.8 \mathrm{~d}^{-1}$ are reported for different cyanobacteria species, such as Synechocysits sp. (Kim et al., 2015) and Cyanothece sp. (Zhang et al., 2015). On the other hand, Salleh et al. (2017) reported a value of $6 \mathrm{~d}^{-1}$ for Anabaena variabilis. It should be taken into account that this parameter represents a growth condition that can hardly occur in reality where, even if nutrients are supplied in excess, light will always play an important effect on the actual growth and respiration of the photosynthetic microorganisms. It should be noticed, in addition, that the physical meaning of such a parameter is different from that of the classical Monod function, because the dependence on light intensity is described with a Haldane-like model. Accordingly, the maximum specific growth rate for photosynthetic organisms should be described from a different perspective than for heterotrophic organisms. In fact, it represents an ideal value, useful to correctly describe the growth of the organisms from a mass balance and kinetic point of view, rather than an actual value reachable under specific growth conditions. This different approach appears reasonable when considering the complex metabolisms of photosynthetic organisms. Different metabolic pathways are in fact combined to sustain growth, as a result of complex mechanisms ranging from light capture efficiency, the ratio of the respiration rate, additional effects of light dissipation and energy losses for nitrogen fixation, that are all included in the maintenance term.

\section{CONCLUSIONS}

In this work we propose a method to reliably determine kinetic parameters of photosynthetic microorganisms, in particular the maximum specific growth rate. Specifically, the method was applied to describe the behavior of the $\mathrm{N}$-fixing cyanobacterium Anabaena PCC7122, whose growth rate is influenced by not only light and temperature, but may also be limited by the reduced concentration of dissolved atmospheric nitrogen. By means of 
well-validated respirometric tests, it was possible to measure the kinetic parameters describing the effect of light, temperature and nitrogen on the cyanobacterium growth rate. In particular, the half-saturation of $\mathrm{N}$ resulted lower compared to that of green microalagae, but comparable to that of other cyanobacteria. Moreover, the value of $3 \mathrm{mg} \mathrm{L} \mathrm{L}^{-1}$ found here suggests that Anabaena growth under $\mathrm{N}$-fixing conditions is not significantly limited by atmospheric nitrogen solubility (about $13 \mathrm{mg} \mathrm{L}^{-1}$ at ambient conditions). This was also confirmed by continuous cultivation experiments, which showed only slight differences between the productivities obtained with and without additional supply of nitrates. The evaluation of the specific maintenance rate showed that this parameter is affected by the light intensity, with more energy being dissipated under high light conditions, and by the nitrogen source, with $\mathrm{N}$-fixation requiring more energy for cell maintenance. Finally, the maximum specific growth rate could be determined by applying the comprehensive and fully determined kinetic model in the material balance of the continuous PBR, obtaining a constant value.

The proposed method can be easily applied to any photosynthetic microorganism as a way to quickly quantify the effect of the main process variables on the growth kinetics, and

\section{REFERENCES}

Allen, M. B., and Arnon, D. J. (1955). Studies on nitrogen-fixing blue-green algae. I. Growth and nitrogen-fixation by Anabaena cylindrica Lemn. Plant Physiol. 30, 366-372. doi: 10.1104/pp.30.4.366

Barbera, E., Sforza, E., and Bertucco, A. (2015). Maximizing the production of Scenedesmus obliquus in photobioreactors under different irradiation regimes: experiments and modeling. Bioprocess Biosyst. Eng. 38, 2177-2188. doi: 10.1007/s00449-015-1457-9

Bernard, O., Mairet, F., and Chachuat, B. (2015). "Modelling of microalgae culture systems with applications to control and optimization," in Advances in Biochemical Engineering Biotechnology, eds C. Posten and S. Feng Chem (Cham: Springer), 59-87. doi: 10.1007/10_2014_287

Bernard, O., and Rémond, B. (2012). Validation of a simple model accounting for light and temperature effect on microalgal growth. Bioresour. Technol. 123, 520-527. doi: 10.1016/j.biortech.2012.07.022

Cornet, J. F., Dussap, C. G., Cluzel, P., and Dubertret, G. (1992). A structured model for simulation of cultures of the Cyanobacterium Spirulina platensis in photobioreactors: II. Identification of kinetic parameters under light and mineral limitations. Biotechnol. Bioeng. 40, 826-834. doi: 10.1002/bit.260400710

Darvehei, P., Bahri, P. A., and Moheimani, N. R. (2018). Model development for the growth of microalgae: a review. Renew. Sust. Energy Rev. 97, 233-258. doi: 10.1016/j.rser.2018.08.027

Decostere, B., Janssens, N., Alvarado, A., Maere, T., Goethals, P., Van Hulle, S. W. H., et al. (2013). A combined respirometer-titrimeter for the determination of microalgae kinetics: experimental data collection and modelling. Chem. Eng. J. 222, 85-93. doi: 10.1016/j.cej.2013.01.103

Fernandes, B. D., Mota, A., Teixeira, J. A., and Vicente, A. A. (2015). Continuous cultivation of photosynthetic microorganisms: approaches, applications and future trends. Biotechnol. Adv. 33, 1228-1245. doi: 10.1016/j.biotechadv.2015.03.004

Fogg, G. E. (1944). Growth and heterocyst production in Anabaena cylindrica Lemm. New Phytol. 43, 164-175. doi: 10.1111/j.1469-8137.1944.tb05012.x

Gons, H. J., and Mur, L. R. (1980). Energy requirements for growth and maintenance of Scenedesmus protuberans fritsch in light-limited continuous cultures. Arch. Microbiol. 125, 9-17. doi: 10.1007/BF00403192

Haldane, J. B. S. (1930). Enzymes. London: Longmans. use this to perform process simulations aimed at design and control of large-scale production processes.

\section{DATA AVAILABILITY STATEMENT}

The datasets generated for this study are included in the manuscript/Supplementary Files.

\section{AUTHOR CONTRIBUTIONS}

EB and ES contributed the conception and design of the study. $A G$ and $L B$ performed the experiments. AG and EB wrote the first draft of the manuscript. EB, ES, and AG wrote the sections of the manuscript. ES and $\mathrm{AB}$ discussed the results. All authors contributed to manuscript revision, read, and approved the submitted version.

\section{SUPPLEMENTARY MATERIAL}

The Supplementary Material for this article can be found online at: https://www.frontiersin.org/articles/10.3389/fbioe. 2019.00274/full\#supplementary-material

Halterman, S. G., and Toetz, D. W. (1984). Kinetics of nitrate uptake by freshwater algae. Hydrobiologia 114, 209-214. doi: 10.1007/BF00031872

Hattori, A. (1962). Light-induced reduction of nitrate, nitrite and hydroxylamine in a blue-green alga, Anabaena cylindrica. Plant Cell Physiol. 3, 355-369. doi: $10.1007 / \mathrm{BF} 00446866$

Janssen, M., Tramper, J., Mur, L. R., and Wijffels, R. H. (2003). Enclosed outdoor photobioreactors: light regime, photosynthetic efficiency, scale-up, and future prospects. Biotechnol. Bioeng. 81, 193-210. doi: 10.1002/bit. 10468

Khan, M. I., Shin, J. H., and Kim, J. D. (2018). The promising future of microalgae: current status, challenges, and optimization of a sustainable and renewable industry for biofuels, feed, and other products. Microb. Cell Fact. 17, 1-21. doi: 10.1186/s12934-018-0879-x

Kim, H.-W., Park, S., and Rittmann, B. E. (2015). Multi-Component Kinetics for the Growth of the Cyanobacterium Synechocystis Sp. PCC6803. Environ. Eng. Res. 20, 347-355. doi: 10.4491/eer.2015.033

Kliphuis, A. M., Klok, A. J., Martens, D. E., Lamers, P. P., Janssen, M., and Wijffels, R. H. (2012). Metabolic modeling of Chlamydomonas reinhardtii: energy requirements for photoautotrophic growth and maintenance. J. Appl. Phycol. 24, 253-266. doi: 10.1007/s10811-011-9674-3

Lam, M. K., Lee, K. T., and Mohamed, A. R. (2012). Current status and challenges on microalgae-based carbon capture. Int. J. Greenh. Gas Con. 10, 456-469. doi: 10.1016/j.ijggc.2012.07.010

Monod, J. (1949). The growth of bacterial cultures. Annu. Rev. Microbiol. 3, 371-394. doi: 10.1146/annurev.mi.03.100149.002103

Moreno, J., Ángeles Vargas, M., Rodríguez, H., Rivas, J., and Guerrero, M. G. (2003). Outdoor cultivation of a nitrogen-fixing marine Cyanobacterium, Anabaena sp. ATCC 33047. Biomol. Eng. 20, 191-97. doi: 10.1016/S1389-0344(03)00051-0

Moreno, J., Rodríguez, H., Angeles Vargas, M., Rivas, J., and Guerrero, M. G. (1995). Nitrogen-fixing cyanobacteria as source of phycobiliprotein pigments. Composition and growth performance of ten filamentous heterocystous strains. J. Appl. Phycol. 7, 17-23. doi: 10.1007/BF00003545

Phillips, M. J., and Roberts, R. J. (1985). The toxicity of the cyanobacterium Microcystis aeruginosa to rainbow trout, Salmo gairdneri. J. Fish Dis. 8, 339-344. doi: 10.1111/j.1365-2761.1985.tb00953.x

Pirt, S. J. (1965). The maintenance energy of bacteria in growing cultures. Proc. $R$. Soc. Lond. Ser. B Biol. Sci. 163, 224-231. doi: 10.1098/rspb.1965.0069 
Quiblier, C., Susanna, W., Isidora, E.-S., Mark, H., Aure, V., and Jean-Franc, H. (2013). A review of current knowledge on toxic benthic freshwater cyanobacteria E ecology, toxin production and risk management. Water Res. 47, 5464-5479. doi: 10.1016/j.watres.2013.06.042

Ramos Tercero, E. A., Sforza, E., Morandini, M., and Bertucco, A. (2014). Cultivation of chlorella protothecoides with urban wastewater in continuous photobioreactor: biomass productivity and nutrient removal. Appl. Biochem. Biotechnol. 172, 1470-1485. doi: 10.1007/s12010-013-0629-9

Ras, M., Steyer, J. P., and Bernard, O. (2013). Temperature effect on microalgae: a crucial factor for outdoor production. Rev. Envir. Sci. Biotechnol. 12, 153-164. doi: 10.1007/s11157-013-9310-6

Rinanti, A. (2016). "Biotechnology carbon capture and storage by microalgae to enhance $\mathrm{CO}_{2}$ removal efficiency in closed- system photobioreactor," in Algae-Organisms for Imminent Biotechnology, eds N. Thajuddin, and D. Dharumadurai (IntechOpen), 133-156. doi: 10.5772/62915

Rossi, S., Bellucci, M., Marazzi, F., Mezzanotte, V., and Ficara, E. (2018). Activity assessment of microalgal-bacterial consortia based on respirometric tests. Water Sci. Technol. 78, 207-215. doi: 10.2166/wst.2018.078

Rosso, L., Lobry, J. R., and Flandrois, J. P. (1993). An Unexpected correlation between cardinal temperatures of microbial growth highlighted by a new model. J. Theor. Biol. 162, 447-463. doi: 10.1006/jtbi.1993.1099

Rowley, W. M. (2010). Nitrogen and Phosphorus Biomass-Kinetic Model for Chlorella Vulgaris in a Biofuel Production Scheme. BiblioScholar. Available online at: https://www.bookdepository.com/Nitrogen-and-PhosphorusBiomass-Kinetic-Model-for-Chlorella-Vulgaris-in-Biofuel-ProductionScheme-William-M-Rowley/9781249592921

Salleh, S. F., Kamaruddin, A., Uzir, M. H., Mohamed, A. R., and Shamsuddin, A. H. (2017). Modeling the light attenuation phenomenon during photoautotrophic growth of A. variabilis ATCC 29413 in a Batch Photobioreactor. J. Chem. Technol. Biotechnol. 92, 358-366. doi: 10.1002/jctb.5013

Sforza, E., Enzo, M., and Bertucco, A. (2014a). Design of microalgal biomass production in a continuous photobioreactor: an integrated experimental and modeling approach. Chem. Eng. Res. Des. 92, 1153-62. doi: 10.1016/j.cherd.2013.08.017

Sforza, E., Gris, B., De Farias Silva, C. E., Morosinotto, T., and Bertucco, A. (2014b). Effects of light on cultivation of Scenedesmus obliquus in batch and continuous flat plate photobioreactor. Chem. Eng. Trans. 38, 211-216. doi: $10.3303 /$ CET1438036

Sforza, E., Pastore, M., Barbera, E., and Bertucco, A. (2019). Respirometry as a tool to quantify kinetic parameters of microalgal mixotrophic growth. Bioprocess Biosyst. Eng. 42, 839-851. doi: 10.1007/s00449-019-02087-9
Sforza, E., Urbani, S., and Bertucco, A. (2015). Evaluation of maintenance energy requirements in the cultivation of Scenedesmus obliquus: effect of light intensity and regime. J. Appl. Phycol. 27, 1453-1462. doi: 10.1007/s10811-0140460-x).

Singh, S., and Datta, P. (2007). Outdoor evaluation of herbicide resistant strains of Anabaena variabilis as biofertilizer for rice plants. Plant Soil 296, 95-102. doi: 10.1007/s11104-007-9293-6

Stanbury, P. F., Whitaker, A., and Hall, S. J. (2016). "Microbial growth kinetics," in Principles of Fermentation Technology, 3rd Edn (ButterworthHeinemann), 21-74. Available online at: https://www.sciencedirect.com/book/ 9780080999531/principles-of-fermentation-technology

Takache, H., Cgristophe, G., Cornet, J.-F., and Pruvost, J. (2010). Experimental and theoretical assessment of maximum productivities for the microalgae Chlamydomonas reinhardtii in two different geometries of photobioreactors. Biotechnol. Progress 26, 431-440. doi: 10.1002/btpr.356.

Trilli, A. (1990). "Kinetics of secondary metabolite production," in Microbial Growth Dynamics, eds R. K. Poole, M. J. Bazin, and C. W. Keevil (Oxford: IRL Press), 103-26.

Yun, Y. S., and Park, J. M. (2003). Kinetic modeling of the light-dependent photosynthetic activity of the green microalga Chlorella vulgaris. Biotechnol. Bioeng. 83, 303-311. doi: 10.1002/bit.10669

Zaimes, G. G., and Khanna, V. (2013). Microalgal biomass production pathways: evaluation of life cycle environmental impacts. Biotechnol. Biofuels 6:88. doi: 10.1186/1754-6834-6-88

Zhang, D., Dechatiwongse, P., and Hellgardt, K. (2015). Modelling light transmission, cyanobacterial growth kinetics and fluid dynamics in a laboratory scale multiphase photo-bioreactor for biological hydrogen production. Algal Res. 8, 99-107. doi: 10.1016/j.algal.2015. 01.006

Conflict of Interest: The authors declare that the research was conducted in the absence of any commercial or financial relationships that could be construed as a potential conflict of interest.

Copyright (c) 2019 Barbera, Grandi, Borella, Bertucco and Sforza. This is an openaccess article distributed under the terms of the Creative Commons Attribution License (CC BY). The use, distribution or reproduction in other forums is permitted, provided the original author(s) and the copyright owner(s) are credited and that the original publication in this journal is cited, in accordance with accepted academic practice. No use, distribution or reproduction is permitted which does not comply with these terms. 


\section{NOMENCLATURE}

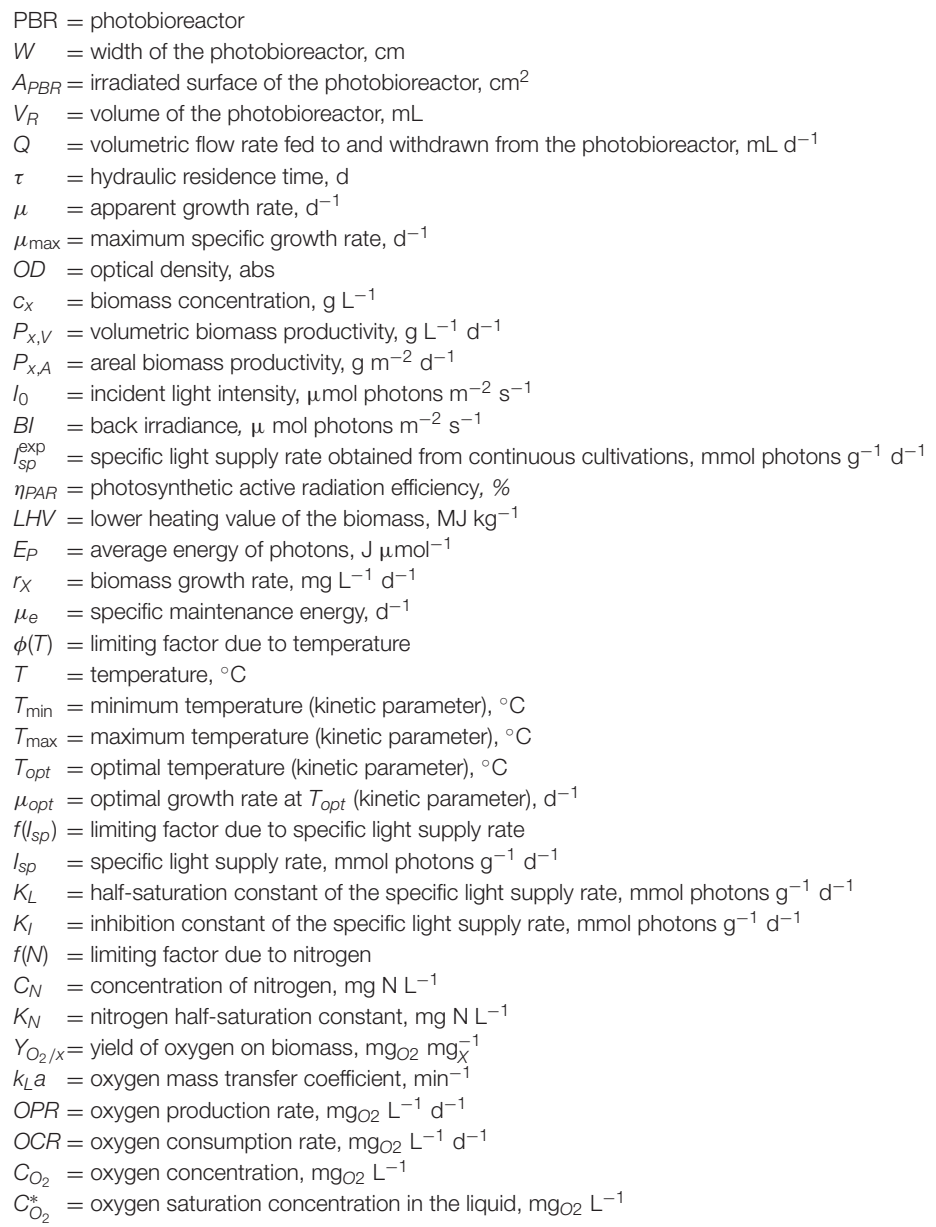

